\title{
Development of mnemonic discrimination during childhood
}

\author{
Leslie Rollins ${ }^{1}$ and Elizabeth B. Cloude ${ }^{1,2}$ \\ ${ }^{1}$ Department of Psychology, Christopher Newport University, Newport News, Virginia 23606, USA; ${ }^{2}$ Department of Psychology \\ at North Carolina State University, Raleigh, North Carolina 27607, USA
}

\begin{abstract}
The present study examined mnemonic discrimination in 5- and 6-yr-old children, 8- and 9-yr-old children, 11- and 12-yr-old children, and young adults. Participants incidentally encoded pictorial stimuli and subsequently judged whether targets (i.e., repeated stimuli), lures (i.e., mnemonically related stimuli), and foils (i.e., novel stimuli) were old, similar, or new. Compared to older age groups, younger children were more likely to (1) incorrectly identify lures as "old" (rather than "similar") and (2) fail to recognize lures altogether, especially when lures were more mnemonically distinct from targets. These results suggest age-related improvements in pattern separation and pattern completion during childhood.
\end{abstract}

Declarative memory improves substantially during childhood; however, the processes underlying the development of declarative memory are not well understood. Improvements in pattern separation and pattern completion may support memory development during childhood. Pattern separation reduces interference by creating distinct memory representations from overlapping input (Yassa and Stark 2011). The complementary process of pattern completion supports the retrieval of stored memory representations when provided with partial or degraded input (Yassa and Stark 2011). Subregions of the hippocampus are differentially biased toward pattern completion or pattern separation (for reviews, see Guzowski et al. 2004; Yassa and Stark 2011; Kirwan and Nash 2016). Computational models (e.g., Norman and O'Reilly 2003) and research with animals (e.g., Lee et al. 2004; Leutgeb et al. 2004; Vazdarjanova and Guzowski 2004) suggest that the dentate gyrus supports pattern separation, the CA1 subfield supports pattern completion, and the CA3 subfield is differentially biased toward pattern separation and pattern completion depending on the degree of overlap between the input and the stored representation.

In humans, researchers often tax pattern separation by requiring participants to distinguish among targets (i.e., repeated stimuli), lures (i.e., stimuli that are mnemonically related to targets), and foils (i.e., novel stimuli; Kirwan and Stark 2007). While adults perform this task, the DG/CA3 subregions exhibit suppressed activity to repetitions relative to lures and first presentations, a pattern consistent with pattern separation (Bakker et al. 2008; Lacy et al. 2011). In contrast, the CA1 subfield shows suppressed activity to repetitions and lures relative to first presentations, a pattern consistent with pattern completion (Bakker et al. 2008; Lacy et al. 2011). Further, activation of the CA1 subfield varies continuously as a function of the degree of mnemonic similarity between the targets and lures whereas activation of the CA3 subregion does not (Lacy et al. 2011).

The hippocampal formation exhibits prolonged structural maturation (Insausti et al. 2010; Lavenex and Lavenex 2013; Lee et al. 2014; Daugherty et al. 2017), and subregions of the hippocampal formation mature at different rates during childhood (for review, see Lavenex and Lavenex 2013). The dentate gyrus and CA3 subfield show protracted structural development relative to

Corresponding author: leslie.rollins@cnu.edu

Article is online at http://www.learnmem.org/cgi/doi/10.1101//m.047142.117. the subicular complex as well as CA1 and CA2 subfields (Lavenex and Lavenex 2013). These findings suggest that pattern separation and pattern completion may improve throughout the course of childhood and, due to the reliance on the dentate gyrus, pattern separation would exhibit a more protracted developmental trajectory relative to pattern completion. Only one study to our knowledge has investigated the development of pattern separation to date. Ngo et al. (2018) found 4-yr-olds to be impaired on lure discrimination relative to 6 -yr-olds and young adults. Four-year-olds were biased toward misidentifying lures as old, 6-yr-olds did not reliably identify lures as old or similar, and young adults correctly identified lures as similar. This study represented an initial investigation into the development of pattern separation during childhood. However, given the hippocampal formation continues to show structural changes well into adolescence (Insausti et al. 2010; Lavenex and Lavenex 2013; Lee et al. 2014; Daugherty et al. 2017), the current study examined mnemonic discrimination from early childhood to young adulthood.

This study included eighteen 5- and 6-yr-old children $(M=$ $6.056 \pm 0.129 \mathrm{yr}, 11$ females), twenty 8 - and 9-yr-old children ( $M=9.01 \pm 0.144 \mathrm{yr}, 15$ females), twenty 11 - and 12 -yr-old children $(M=11.79 \pm 0.121 \mathrm{yr}, 10$ females $)$, and 20 young adults $(M=$ $20.562 \pm 0.29 \mathrm{yr}, 18$ females). Four additional individuals participated but were excluded from analyses because of technical error $(n=1)$ or failure to meet inclusion criteria (e.g., ADHD diagnosis; $n=3)$.

Participants completed the mnemonic similarity task (MST; Stark et al. 2013) using a subset of 176 child-appropriate stimuli selected from the Stark Laboratory's database of pictures (http:// faculty.sites.uci.edu/starklab/mnemonic-similarity-task-mst/). Six stimuli were used during the practice phase, 150 stimuli were used during the test phase, and 20 stimuli were used to verify understanding of the terms "same" and "similar." Stimuli for the test phase were equally distributed across five levels of mnemonic similarity used in previous work (e.g., Stark et al. 2013) and divided into three sets of 50 pictures. Stimuli used as targets, lures, and foils were

\footnotetext{
(C) 2018 Rollins and Cloude This article is distributed exclusively by Cold Spring Harbor Laboratory Press for the first 12 months after the full-issue publication date (see http://learnmem.cshlp.org/site/misc/terms.xhtml). After 12 months, it is available under a Creative Commons License (AttributionNonCommercial 4.0 International), as described at http://creativecommons. org/licenses/by-nc/4.0/.
} 
Table 1. Mean proportion of old, similar, and new responses to targets, lures, and foils

\begin{tabular}{|c|c|c|c|c|c|c|c|c|c|}
\hline \multirow[b]{2}{*}{ Age group } & \multicolumn{3}{|c|}{ Targets } & \multicolumn{3}{|c|}{ Lures } & \multicolumn{3}{|c|}{ Foils } \\
\hline & Old & Similar & New & Old & Similar & New & Old & Similar & New \\
\hline -6-yr-olds & $0.671(0.055)$ & $0.146(0.024)$ & $0.181(0.048)$ & $0.418(0.044)$ & $0.316(0.035)$ & $0.266(0.05)$ & $41(0.014)$ & $0.033(0.008)$ & $0.926(0.018)$ \\
\hline 8-9-yr-olds & $0.881(0.016)$ & $0.099(0.016)$ & $0.02(0.004)$ & $0.449(0.028)$ & $0.464(0.027)$ & $0.086(0.014)$ & $0.023(0.007)$ & $0.073(0.016)$ & $0.9(0.018)$ \\
\hline $11-12$-yr-olds & $0.857(0.015)$ & $0.12(0.014)$ & $0.024(0.005)$ & $0.374(0.037)$ & $0.561(0.044)$ & $0.065(0.013)$ & $0.03(0.007)$ & $0.052(0.01)$ & $0.916(0.015)$ \\
\hline Young adults & $0.829(0.024)$ & $0.139(0.019)$ & $0.029(0.009)$ & $0.314(0.024)$ & $0.624(0.028)$ & $0.057(0.014)$ & $0.022(0.007)$ & $0.109(0.018)$ & $0.867(0.019)$ \\
\hline
\end{tabular}

Note. Standard errors in parentheses.

counterbalanced across participants. Participants incidentally encoded 100 stimuli for $2000 \mathrm{msec}$ by making a verbal indoor/outdoor judgment after the stimulus was removed from the screen. At retrieval, participants judged whether 50 targets, 50 lures, and 50 foils were old, similar, or new. A practice phase was used prior to retrieval to ensure task understanding. Following the test phase, participants completed a same/similar verification task. Participants viewed 20 pairs of pictures simultaneously and identified whether each pair was the "same" or "similar." Half of the pairs were the same and half were similar. Similar trials were evenly distributed across the five levels of mnemonic similarity. Verification task performance did not differ among age groups, $F_{(1,73)}=1.053$, $P=0.374, \eta_{\mathrm{p}}^{2}=0.041$.

The mean proportion of old, similar, and new responses to targets, lures, and foils are presented in Table 1 . Recognition memory was indexed by subtracting the proportion of foils identified as old from the proportion of targets identified as old. Although all age groups performed above chance $(0), t s=12.509-49.104$, Ps $<$ 0.001 , a one-way ANOVA with age group as a between-subjects factor showed corrected recognition to differ among age groups, $F_{(3,74)}=11.415, P<0.001, \eta_{\mathrm{p}}^{2}=0.316$ (see Fig. 1). Recognition memory was lower in 5- and 6-yr-old children than all older age groups ( $P s \leq 0.001)$, which performed similarly $(P s=1.0)$.

To examine age-related differences in lure discrimination, difference scores were calculated by subtracting the proportion of lures identified as old from the proportion of lures identified as similar (Toner et al. 2009). Negative values indicate misidentification of lures as old whereas positive values indicate accurate identification of lures as similar. A one-way ANOVA with age group as a between-subjects factor showed lure discrimination to differ among age groups, $F_{(3,74)}=8.404, P<0.001, \eta_{\mathrm{p}}^{2}=0.254$ (see Fig. 1). Pairwise comparisons revealed 5- and 6-yr-old children to be more likely to misidentify lures as old than 11- and 12-yr-old children and adults $(P s<0.011)$ but not 8 - and 9-yr-old children $(P=1.0)$. Additionally, 8 - and 9 -yr-old children were more likely to misidentify lures than adults $(P=0.007)$ but not 11- and 12-yr-old children $(P=$ $0.308)$. Lure discrimination continued to differ as a function of age group, $F_{(3,73)}=$ 8.148, $P<0.001, \eta_{\mathrm{p}}^{2}=0.251$, even when corrected recognition was included as a covariate in the analysis. One sample $t$-tests revealed 11- and 12-yr-old children, $t_{(19)}=2.32, P=0.032$, and young adults, $t_{(19)}=6.213, P<0.001$, accurately classified lures as similar above chance level (0); however, 5- and 6-yr-old children, $t_{(17)}=-1.674, P=0.112$, and 8 - and 9-yr-old children, $t_{(19)}=0.276, P=0.786$, performed at chance.

The effect of mnemonic similarity on lure discrimination was examined by calculating lure discrimination scores separately for each of the five levels of mnemonic similarity (see Fig. 2). A 4 Age Group $\times 5$ Mnemonic Similarity Level Mixed-Model ANOVA revealed main effects of age group, $F_{(3,74)}=8.501, P<0.001$, $\eta_{\mathrm{p}}^{2}=0.256$, and mnemonic similarity, $F_{(4,296)}=124.921, \quad P<$ $0.001, \eta_{\mathrm{p}}^{2}=0.628$, as well as an interaction between age group and mnemonic similarity, $F_{(12,296)}=2.417, P=0.005, \eta_{\mathrm{p}}^{2}=0.098$. Mnemonic similarity impacted lure discrimination in all age groups, $F s=8.864-51.691$, Ps $<0.001, \eta_{\mathrm{p}}^{2} \mathrm{~s}=0.343-0.731$. This finding suggests all age groups understood the task and the stimuli were appropriate for use with children. Discrimination of Level 1 lures, which were the most similar to targets, did not differ among age groups, $F_{(3,74)}=1.833, P=0.149, \eta_{\mathrm{p}}^{2}=0.098$. All age groups showed a propensity to incorrectly identify Level 1 lures as old (rather than similar (Ps $\leq 0.023)$. However, age-related differences were present for Level 2-5 lures, $F s_{(3,74)}=3.377-8.949$, Ps = $<0.023, \eta_{\mathrm{p}}^{2}=0.12-0.266$. As shown in Figure 2, older participants were more effective at discriminating between targets and lures than younger participants. Asterisks in Figure 2 represent the results of one-sample $t$-tests examining whether participated classified lures as "similar" (i.e., positive values) or "old" (i.e., negative values) above chance level $(0 ; P<0.05)$.

Lure recognition was indexed by subtracting the proportion of recognized lures (i.e., lures identified as old or similar) from the proportion of recognized targets (i.e., targets identified as old or similar; see Fig. 1). One-sample $t$-tests showed all age groups to be better at recognizing targets than lures $t s=3.031-4.837$, Ps $<$ 0.007 . However, a one-way ANOVA with age group as a betweensubjects factor showed lure recognition to differ among age groups, $F_{(3,74)}=3.216, P=0.028, \eta_{\mathrm{p}}^{2}=0.115$ (see Fig. 2). Pairwise comparisons revealed differences in recognition performance between targets and lures to be larger for 5- and 6-yr-old children

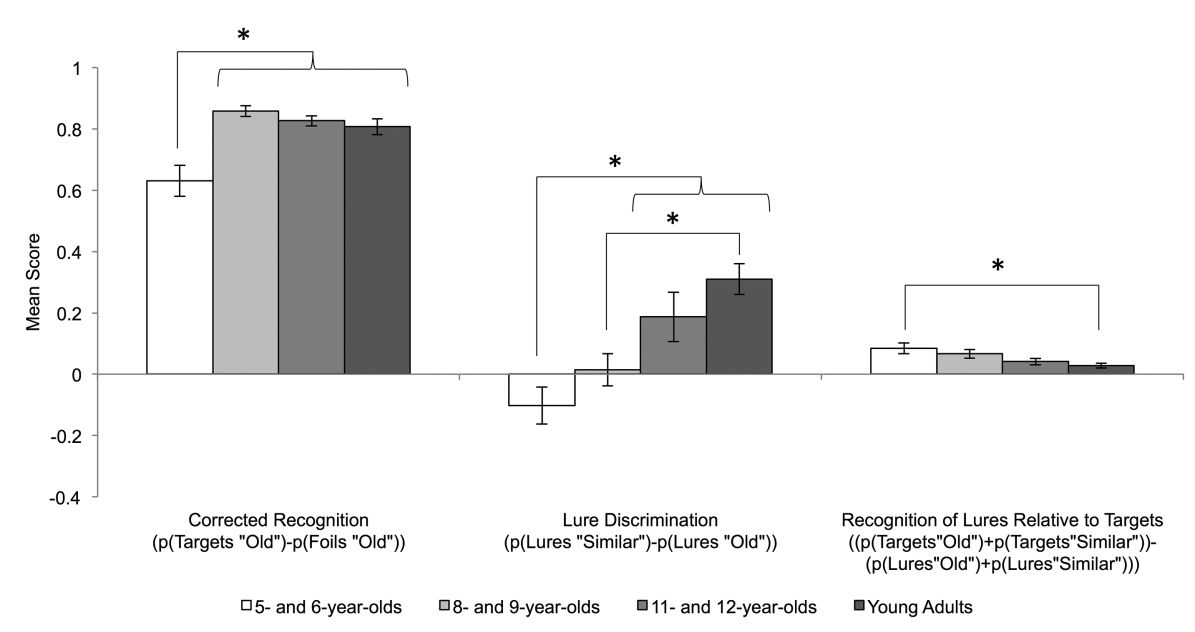

Figure 1. Corrected recognition, lure discrimination, and lure recognition scores for each age group. Error bars reflect standard errors. ( $\left.{ }^{*}\right) P<0.05$. 


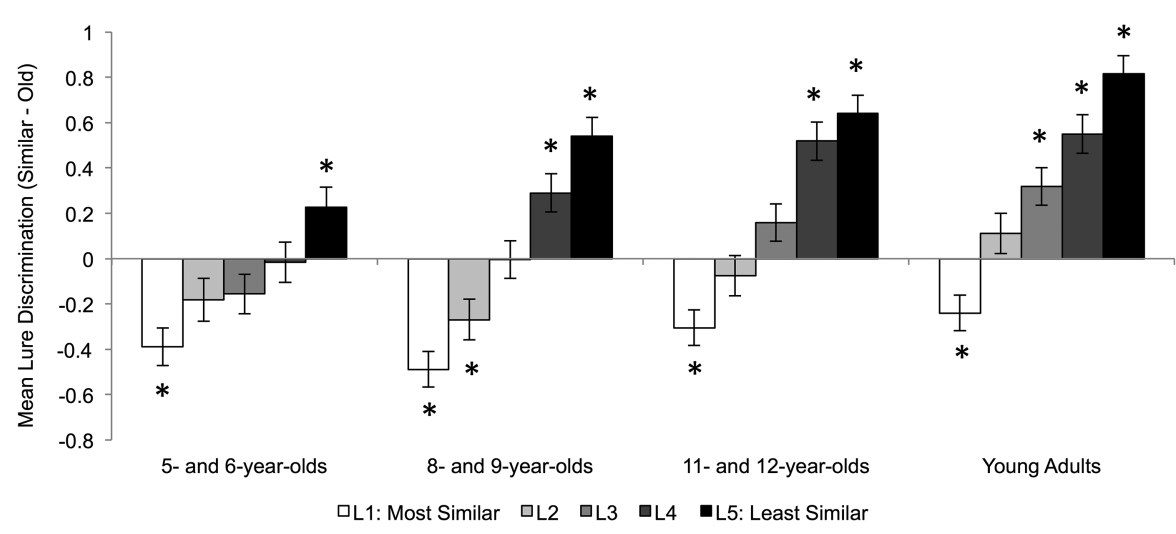

Figure 2. Mean lure discrimination score for each level of mnemonic similarity and age group. Error bars reflect standard errors. $\left(^{*}\right) P<0.05$ for one-sample $t$-tests comparing lure discrimination to chance performance (0). Positive values reflect accurately identifying lures as similar whereas negative values reflect inaccurately identifying lures as old.

than adults $(P=0.041)$. No other group difference was significant (Ps $\geq 0.232)$.

To assess the influence of mnemonic similarity on lure recognition, we conducted a 4 Age Group $\times 5$ Mnemonic Similarity Level Mixed-Model ANOVA on the proportion of recognized lures for each level of mnemonic similarity (see Fig. 3). The analysis revealed a main effect of age group, $F_{(3,74)}=13.045, P<0.001, \eta_{\mathrm{p}}^{2}=0.346$, and mnemonic similarity, $F_{(4,296)}=7.05, P<0.001, \eta_{\mathrm{p}}^{2}=0.087$, as well as an interaction between mnemonic similarity and age group, $F_{(12,296)}=3.872, P<0.001, \eta_{\mathrm{p}}^{2}=0.136$. Mnemonic similarity influenced lure recognition in 5- and 6-yr-old children, $F_{(4,68)}=6.959, P$ $<0.001, \eta_{\mathrm{p}}^{2}=0.29$, and 8- and 9-yr-old children, $F_{(4,76)}=4.009, P=$ $0.005, \eta_{\mathrm{p}}^{2}=0.174$, but not 11- and 12-yr-old children, $F_{(4,76)}=$ 2.317, $P=0.065, \eta_{\mathrm{p}}^{2}=0.109$, and young adults, $F_{(4,76)}=0.899, P$ $=0.437, \eta_{\mathrm{p}}^{2}=0.045$. Pairwise comparisons showed 5- and 6-yr-old children recognized Level 4 lures significantly less than Level $1(P=$ 0.004) and Level 2 lures $(P=0.002)$; no other difference between levels was significant ( $P S \geq 0.185$ ). Similarly, 8- and 9-yr-old children recognized Level 5 lures marginally less than Level 1 lures $(P=0.066)$; no other difference between levels approached significance (Ps $\geq 0.119)$.

These results reveal age-related improvements in overall memory recognition, lure discrimination, and lure recognition during childhood. These findings are consistent with the development of recognition more generally as well as the development of pattern separation and pattern completion. To date, only one study has examined the development of pattern separation in children (Ngo et al. 2018). Ngo et al. (2018) reported an improvement in lure discrimination between 4 and $6 \mathrm{yr}$ of age but no significant difference between 6-yr-old children and young adults. Our results showed lure discrimination continued to improve into middle childhood. Specifically, 5- and 6-yr-old children exhibited poorer lure discrimination than 11and 12-yr-old children and young adults, and 8- and 9-yr-old children exhibited poorer lure discrimination than young adults. Methodological differences likely account for why we observed a more extended age-related improvement in pattern separation than Ngo et al. (2018), and protracted improvements in lure discrimination are consistent with research

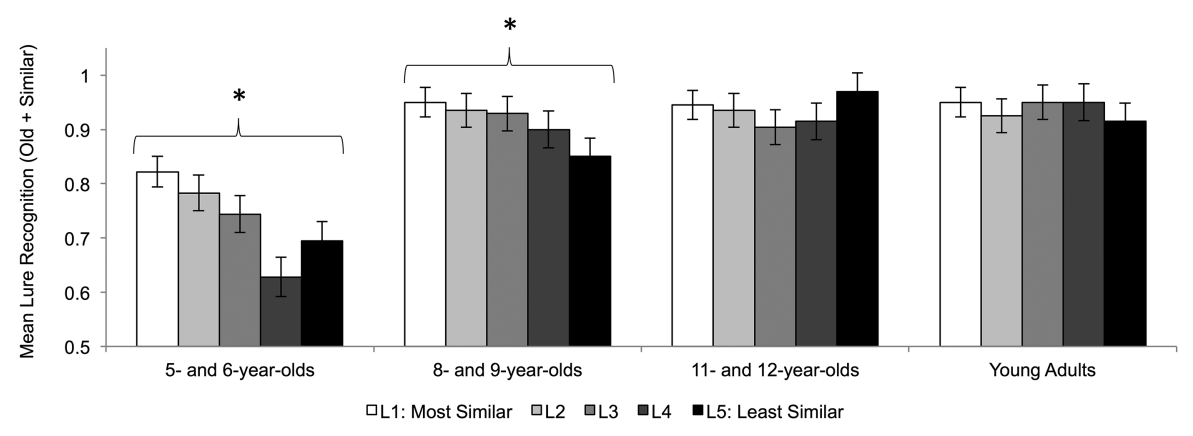

Figure 3. Mean lure recognition score for each level of mnemonic similarity and age group. Error bars reflect standard errors. Mnemonic similarity impacted lure recognition in 5- and 6-yr-olds and 8- and 9 -yr-olds $(P s<0.05)$ but not 11 - and 12 -yr-olds and young adults.

on the structural and functional development of the dentate gyrus and CA3 subregion of the hippocampus, which are biased toward pattern separation (Bakker et al. 2008; Insausti et al. 2010; Lacy et al. 2011; Lavenex and Lavenex 2013; Lee et al. 2014; Daugherty et al. 2017).

Multiple results from the present study are consistent with the development of pattern completion during childhood. Pattern completion would support the recognition of targets and lures. However, due to the difference between the input and the stored representation, lure recognition is more taxing on pattern completion than target recognition. Fiveand 6-yr-old children exhibited impairment in the recognition of both targets and lures. Although an overall bias to respond "new" could account for the age-related difference in corrected recognition, it would not explain why 5- and 6-yr-old children recognized lures at a lower rate than targets. This pattern of results could be explained by a deficit in pattern completion or by age-related differences in response thresholds. To address this question, future research could adopt the design used in Experiment 4 by Stark et al. (2015) by requiring participants to make old/new judgments based on gist (i.e., respond "old" to targets or lures) or veridical memory traces (i.e., respond "old" only to targets). Further, lures varied in mnemonic similarity to previously encoded items. Items less mnemonically similar to stored representations would be more taxing on the process of pattern completion. Lure recognition varied as a function of mnemonic similarity in 5and 6-yr-old children and 8- and 9-yr-old children but not 11and 12-yr-old children and young adults. Therefore, younger children less accurately retrieved a stored representation when presented with increasingly degraded input, which, by definition, suggests younger children are deficient in pattern completion. The interpretation of these findings as reflecting age-related differences in pattern completion is consistent with studies of rodents that have drawn conclusions about pattern completion by systematically varying retrieval cues (e.g., Nakazawa et al. 2002; Gold and Kesner 2005). However, an important caveat of this conclusion is that the MST was designed to tax pattern separation, rather than pattern completion; thus, we are drawing conclusions about pattern completion with caution.

The current results also have implications for theories of episodic memory development. Age-related improvements in the 
development of episodic memory during childhood have been attributed to the development of multiple processes, including recollection, binding, and controlled processes (e.g., encoding strategies and metacognitive monitoring; for reviews, see Ghetti and Lee 2011; Ghetti and Bunge 2012). The current investigation and that of Ngo et al. (2018) suggest the development of pattern separation and pattern completion likely contribute to age-related improvements in episodic memory. Future studies should aim to identify the neurobiological bases of pattern separation and pattern completion across development as well as investigate how these processes interact or contribute to other processes known to develop throughout childhood, such as recollection. For example, Trelle et al. (2017) recently demonstrated that impaired controlled processes partially accounted for age-related deficits in pattern separation in older adults.

In conclusion, mnemonic discrimination improves throughout childhood. Age-related improvements in lure discrimination and lure recognition provide support for the development of pattern separation and pattern completion, respectively. These conclusions are consistent with research on the structural development of the hippocampal formation and have important implications for theories of and future research on episodic memory development.

\section{Acknowledgments}

This research was supported by Christopher Newport University. The authors would like to thank Hannah Nierle for assistance with data collection as well as Tracy Riggins and Kelsey Canada for their helpful comments on this paper.

\section{References}

Bakker A, Kirwan CB, Miller M, Stark CEL. 2008. Pattern separation in the human hippocampal CA3 and dentate gyrus. Science 319: 1640-1642.

Daugherty AM, Flinn R, Ofen N. 2017. Hippocampal CA3-dentate gyrus volume uniquely linked to improvement in associative memory from childhood to adulthood. Neuroimage 153: $75-85$.

Ghetti S, Bunge SA. 2012. Neural changes underlying the development of episodic memory during middle childhood. Dev Cogn Neurosci 2: 381-395.

Ghetti S, Lee J. 2011. Children's episodic memory. Wiley Interdiscip Rev Cogn Sci 2: $365-373$.

Gold AE, Kesner RP. 2005. The role of the CA3 subregion of the dorsal hippocampus in spatial pattern completion in the rat. Hippocampus 15: 808-184.

Guzowski JF, Knierim JJ, Moser EI. 2004. Ensemble dynamics of hippocampal regions CA3 and CA1. Neuron 44: 581-584.
Insausti R, Cebada-Sánchez S, Marcos P. 2010. Postnatal development of the human hippocampal formation. Adv Anat Embryol Cell Biol 206: 1-86.

Kirwan CB, Nash MI. 2016. Resolving interference: The role of the human hippocampus in pattern separation. In The neurobiological basis of memory (ed. Jackson PA, Chiba AA, Berman RF, Ragozzino ME), pp. 151-173. Publisher Springer International Publishing, Switzerland.

Kirwan CB, Stark CEL. 2007. Overcoming interference: An fMRI investigation of pattern separation in the medial temporal lobe. Learn Mem 14: 625-633.

Lacy JW, Yassa MA, Stark SM, Muftuler LT, Stark CEL. 2011. Distinct pattern separation related transfer functions in human CA3/dentate and CA1 revealed using high-resolution fMRI and variable mnemonic similarity. Learn Mem 18: 15-18.

Lavenex P, Lavenex PB. 2013. Building hippocampal circuits to learn and remember: insights into the development of human memory. Behav Brain Res 254: 8-21.

Lee IL, Yoganarasimha D, Rao G, Knierim JJ. 2004. Comparison of population coherence and place cells in hippocampal subfields CA1 and CA3. Nature 430: 456-459.

Lee JK, Ekstrom AD, Ghetti S. 2014. Volume of hippocampal subfields and episodic memory in childhood and adolescence. Neuroimage 94: 162-171.

Leutgeb S, Leutgeb JK, Treves A, Moser M-B, Moser EI. 2004. Distinct ensemble codes in hippocampal areas CA3 and CA1. Science 305: 1295-1298.

Nakazawa K, Quirk MC, Chitwood RA, Watanabe M, Yeckel MF, Sun LD, Kato A, Carr CA, Johnston D, Wilson MA, et al. 2002. Requirement for hippocampal CA3 NDMA receptors in associative memory recall. Science 297: 211-218.

Ngo CT, Newcombe NS, Olson IR. 2018. The ontogeny of relational memory and pattern separation. Dev Sci 21. doi: 10.1111/desc.12556

Norman KA, O'Reilly RC. 2003. Modeling hippocampal and neocortical contributions to recognition memory: a complementary-learning-systems approach. Psychol Rev 110: 611-646.

Stark SM, Yassa MA, Lacy JW, Stark CEL. 2013. A task to assess behavioral pattern separation (BPS) in humans: data from healthy aging and mild cognitive impairment. Neuropsychologia 51: 2442-2449.

Stark SM, Stevenson R, Wu C, Rutledge S, Stark CEL. 2015. Stability of age-related deficits in the mnemonic similarity task across task variations. Behav Neurosci 129: 257-268.

Toner CK, Pirogovsky E, Kirwan CB, Gilbert PE. 2009. Visual object pattern separation deficits in nondemented older adults. Learn Mem 16: 338-342.

Trelle AN, Henson RN, Green DAE, Simons JS. 2017. Declines in representational quality and strategic retrieval processes contribute to age-related increases in false recognition. J Exp Psychol Learn Mem Cogn 43: $1883-1897$.

Vazdarjanova A, Guzowski JF. 2004. Differences in hippocampal neuronal population responses to modifications of an environmental context: evidence for distinct, yet complementary, functions of CA3 and CA1 ensembles. J Neurosci 24: 6489-6496.

Yassa MA, Stark CL. 2011. Pattern separation in the hippocampus. Trends Neurosci 34: 515-525.

Received November 21, 2017; accepted in revised form February 5, 2018. 


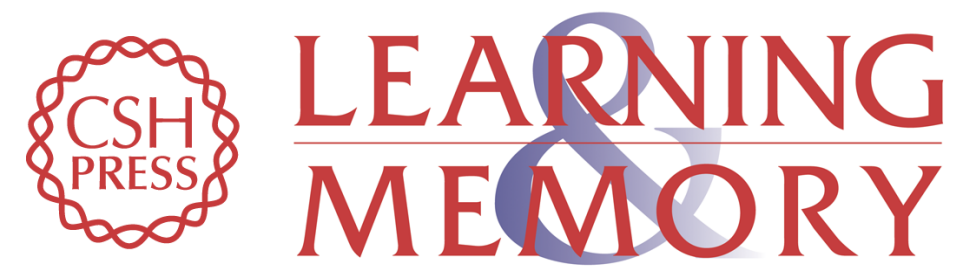

\title{
Development of mnemonic discrimination during childhood
}

\author{
Leslie Rollins and Elizabeth B. Cloude
}

Learn. Mem. 2018, 25:

Access the most recent version at doi:10.1101//m.047142.117

References This article cites 22 articles, 6 of which can be accessed free at: http://learnmem.cshlp.org/content/25/6/294.full.html\#ref-list-1

Creative This article is distributed exclusively by Cold Spring Harbor Laboratory Press for the Commons License first 12 months after the full-issue publication date (see http://learnmem.cshlp.org/site/misc/terms.xhtml). After 12 months, it is available under a Creative Commons License (Attribution-NonCommercial 4.0 International), as described at http://creativecommons.org/licenses/by-nc/4.0/.

Email Alerting Receive free email alerts when new articles cite this article - sign up in the box at the Service top right corner of the article or click here. 